\title{
Hydroxylated N-doped carbon nanotube-sulfur composites as cathodes for high- performance lithium-sulfur batteries
}

\author{
Jun Seop Lee ${ }^{1}$ and Arumugam Manthiram ${ }^{1} *$ \\ Jun Seop Lee: $\underline{\text { lino0923@gmail.com Arumugam Mathiram: manth@austin.utexas.edu }}$
}

\section{Abstract}

Despite the higher energy density than the conventional Li-ion cells at a lower cost, commercialization of Li-S batteries is hindered by the insulating nature of sulfur and the dissolution of intermediate polysulfides $\left(\mathrm{Li}_{2} \mathrm{~S}_{\mathrm{X}}, 4<\mathrm{X} \leq 8\right)$ into the electrolyte. We demonstrate here hydroxylated N-doped carbon nanotubes (H-NCNT) as sulfur containers in lithium-sulfur batteries to reduce polysulfide shuttling through an interaction between polysulfides and nitrogen and hydroxyl groups in the H-NCNT. This sulfur-carbon composite electrode with $2.2 \mathrm{mg} \mathrm{cm}^{-2}$ sulfur displays excellent performance with high rate capability (initial capacity of $1,341 \mathrm{mAh} \mathrm{g}^{-1}$ at $\mathrm{C} / 5$ rate and $849 \mathrm{mAh} \mathrm{g}^{-1}$ at $5 \mathrm{C}$ rate), rate stability until 500 cycles (a decay of $0.06 \%$ per cycle). Furthermore, a stable reversible capacity of as high as $\sim 1,081$ $\mathrm{mAh} \mathrm{g}^{-1}$ is realized with a higher sulfur loading of $5.1 \mathrm{mg} \mathrm{cm}^{-2}$.

Keywords: Lithium-sulfur batteries; carbon nanotubes; nitrogen doping; cycle stability; activation poly-sulfide shuttle

*Corresponding author: Tel: +1-512-471-1791; fax: +1-512-471-7681.

E-mail address: manth@austin.utexas.edu (A. Manthiram) 


\section{Introduction}

As an alternative to the currently used lithium-ion batteries, lithium-sulfur ( $\mathrm{Li}-\mathrm{S}$ ) batteries offer great promise owing to the following critical factors: (1) high theoretical capacity $\left(1675 \mathrm{mAh} \mathrm{g}^{-1}\right)$ and specific energy density (2600 $\mathrm{Wh} \mathrm{kg}^{-1}$ ) and (2) high abundance and low cost of sulfur [1-5]. In spite of these merits, severe capacity fade and low sulfur utilization encountered during cycling prohibit the commercialization of Li-S batteries [6-10]. The low cycle stability stems from the high solubility of lithium polysulfides $\left(\mathrm{Li}_{2} \mathrm{~S}_{\mathrm{X}}, 4<\mathrm{X} \leq 8\right)$ in the liquid electrolyte, whereas the low sulfur utilization is mainly caused by the low conductivity of sulfur $\left(5 \times 10^{-28} \mathrm{~S} \mathrm{~cm}^{-2}\right)$ [11-15]. To overcome these limitations, there have been diverse approaches during the past decade [16-19]. In particular, the most promising approach is to fabricate sulfur composites with carbon nanomaterials owing to their excellent adsorption of sulfur. Consequently, various carbon nanomaterials have been implemented as electrically conductive and sulfur-confining framework in the composites [20-23].

To obtain enhanced electrochemical performances with Li-S batteries, the carbon framework in the sulfur composite should have several favorable properties: high electrical conductivity, large pore volume in the structure, and uniform mechanical structure during the redox process [24-27]. However, it is difficult to satisfy all the above requirements due to the contradicting effects of the components. For example, many sulfur-carbon composites exhibit high specific capacities $\left(>1100 \mathrm{~mA} \mathrm{~h}^{-1}\right)$, but with low sulfur loading [28], which defeats the purpose of realizing higher energy densities than that with the current lithium-ion batteries. On the other hand, increasing the sulfur loading often leads to a destruction of the electrical pathway and the conductivity [29].

As a carbon host in the Li-S cathode, there are two approaches of carbon host such as formation of pores and generation of functional groups in the structure. The pores provide high sulfur loading but the cycle stability is poor due to the dissolution of polysulfide during cycling [30,31]. On other hand, the functional groups increase cycling stability of the electrode with high adsorption effect coming from its 
chemical interaction to polysulfide [32]. However, infiltration of the electrolyte to the sulfur component is restricted [33]. Therefore, the coexistence of two-type solutions in the carbon is necessary to solve the limitations of the Li-S electrode.

Herein, we report the synthesis of hydroxylated N-doped carbon nanotube-sulfur composites (S-HNCNT) and their use as a cathode material for Li-S batteries, via a self-degradation method. As the first step material, polypyrrole nanotubes (PPyNT) are formed by a self-degradation process. Then, hydroxylated N-doped carbon nanotubes (H-NCNT) are synthesized by a $\mathrm{KOH}$ activation step. Then, the sulfur is immobilized in the pores with a chemical reduction process. The S-H-NCNT based cathode displays high cycle stability and rate capability, owing to the unique structure of carbon framework. In particular, channels of tubular structure promise an adequate sulfur loading and a high utilization of the sulfur component, while the nitrogen doping and the presence of hydroxyl groups (-OH) lead to enhanced cycle stability and rate capability.

\section{Experimental Section}

\subsection{Materials}

Pyrrole (98\%), methyl orange, and iron chloride $\left(\mathrm{FeCl}_{3}, 97 \%\right)$ were obtained from Aldrich Co.. Potassium hydroxide $(\mathrm{KOH})$, sodium thiosulfate pentahydrate $\left(\mathrm{Na}_{2} \mathrm{~S}_{2} \mathrm{O}_{3} \cdot 5 \mathrm{H}_{2} \mathrm{O}\right)$, polyvinylpyrrolidone (PVP, $\left.\mathrm{M}_{\mathrm{w}}=40,000\right)$, and hydrochloric acid $(\mathrm{HCl})$ were also obtained from Aldrich and used as received without further purification.

\subsection{Fabrication of hydroxylated N-doped carbon nanotubes (H-NCNT)}

As starting material, the polypyrrole nanotubes (PPyNT) were prepared by the self-degradation method. A 1.5 mmole of $\mathrm{FeCl}_{3}$ solution was added into $30 \mathrm{ml}$ of $5 \mathrm{mM}$ methyl orange aqueous solution. Then, 2 mmole of pyrrole monomer was added and stirred at $10^{\circ} \mathrm{C}$ for $12 \mathrm{~h}$. The resulting black precipitate was purified by washing with distilled water several times until the filtrate became transparent. The as prepared black powder was then dried under vacuum at $40^{\circ} \mathrm{C}$ for 12 hours. Hydroxylated n-doped carbon 
nanotubes (H-NCNT) were prepared via $\mathrm{KOH}$ activation process as follows: $400 \mathrm{mg}$ of PPyNT were dispersed in $20 \mathrm{~mL}$ of aqueous $6 \mathrm{M} \mathrm{KOH}$ solution and stirred for $4 \mathrm{~h}$, followed by another $20 \mathrm{~h}$ of static soaking at ambient temperature. The mixed PPyNT solution was purified by repeated centrifugation and multiple washing steps and evaporated at $60^{\circ} \mathrm{C}$. Then, the dried PPyNT were heated at $800^{\circ} \mathrm{C}$ for $1 \mathrm{~h}$ with an argon flow.

\subsection{Fabrication of hydroxylated N-doped carbon nanotube-sulfur composites (S-H-NCNT)}

First, 0.01 mole of sodium thiosulfate pentahydrate $\left(\mathrm{Na}_{2} \mathrm{~S}_{2} \mathrm{O}_{3} \cdot 5 \mathrm{H}_{2} \mathrm{O}\right)$ was dissolved in $200 \mathrm{~mL}$ of deionized (DI) water by stirring. Then, $20 \mathrm{~mL}$ of isopropyl alcohol solution, containing $0.05 \mathrm{~g}$ of activated carbon nanofiber, was suspended in the above solution. $0.04 \mathrm{~g}$ of PVP was inserted to enhance the dispersibility of the H-NCNT in the aqueous solution. A $0.654 \mathrm{~mL}$ of hydrochloric acid (HCl) was then slowly added to the solution to precipitate the sulfur onto the carbon surface. The as-prepared sulfur/carbon mixture was heated up to $155^{\circ} \mathrm{C}$ and kept for $12 \mathrm{~h}$ to facilitate sulfur diffusion into the $\mathrm{H}$ NCNT.

\subsection{Characterization}

A JEOL 6700 was used to acquire field-emission scanning electron microscopy (FE-SEM) images. Transmission electron microscopy (TEM) and high-resolution transmission electron microscopy (HRTEM) images were obtained with JEOL JEM-200CX and JEOL-3010, respectively. X-ray diffraction (XRD) and X-ray photoelectron spectroscopy (XPS) were recorded with an M18XHF SRA (MAC

Science Co.) and AXIS-HIS (KRATOS) equipment. Electron energy loss spectroscopy (EELS) of the composite was performed with a JEOL JEM 2100F.

\subsection{Electrochemical measurements}

The S-a-MCNF based-cathode was prepared by mixing the S-a-MCNF (80 wt.\%), super P (10 wt.\%), and PVDF binder (10 wt.\%) in an N-methyl-2-pyrrolidone (NMP) solvent to form a slurry. The asfabricated slurry with different mass was then cast onto an aluminum foil and was dried in an oven at 
$60^{\circ} \mathrm{C}$ for $12 \mathrm{~h}$ to obtain a uniformly spread cathode film. Then, CR2032-type coin cells consisting of a lithium metal anode, a Celgard separator, and the S-a-MCNF nanocomposite cathode were assembled in an argon-filled glovebox. The electrolyte used was LiTFSI $(1 \mathrm{M})$ and $\mathrm{LiNO}_{3}(0.4 \mathrm{M})$ dissolved in 1,3dioxolane (DOL) and 1,2-dimethoxyethane (DME) (1:1 vol). Galvanostatic discharge was conducted with an Arbin battery cycler at $2.8-1.8 \mathrm{~V}\left(\mathrm{vs} \mathrm{Li} / \mathrm{Li}^{+}\right)$at room temperature.

\section{Results and discussion}

As a first step material, polypyrrole nanotubes (PPyNT) of $c a .100 \mathrm{~nm}$-diameter were formed by a self-degradation method using nanorod template composed of methyl orange and iron chloride. Then, hydroxylated N-doped carbon nanotubes (H-NCNT) were synthesized by an activation step. In detail, the PPyNT were placed in $\mathrm{KOH}$ aqueous solution to generate PPyNT/KOH mixed solution. The PPyNT/KOH mixture was then thermally treated at $800^{\circ} \mathrm{C}$ for $1 \mathrm{~h}$ under an Ar flow to generate hydroxylated carbon nanotubes with small pores in the structure as following chemical reaction [34]:

$$
6 \mathrm{KOH}+\mathrm{C} \leftrightarrows 2 \mathrm{~K}+3 \mathrm{H}_{2}+2 \mathrm{~K}_{2} \mathrm{CO}_{3}
$$

Sulfur was then immobilized in the carbon structure with a chemical reduction process (Fig. 1a). As shown in Fig. 1b and $\mathbf{c}$, the H-NCNT have a rough surface while retaining the tubular structure after the activation process. After the sulfur immobilization step, the fibrous morphology of S-H-NCNT is maintained without the aggregation of the sulfur component on the carbon surface. In addition, transmission electron microscopy (TEM) images and electron energy loss spectroscopy (EELS) dot mapping analysis confirm that the sulfur is filled into the carbon structure rather than being adhered on the external surface (Fig. 1d and e). In contrast, the sulfur composite based on the carbonized polypyrrole nanotubes without the activation (NCNT) displays aggregated sulfur particles on the surface, as seen in Fig. S1. 
(a)
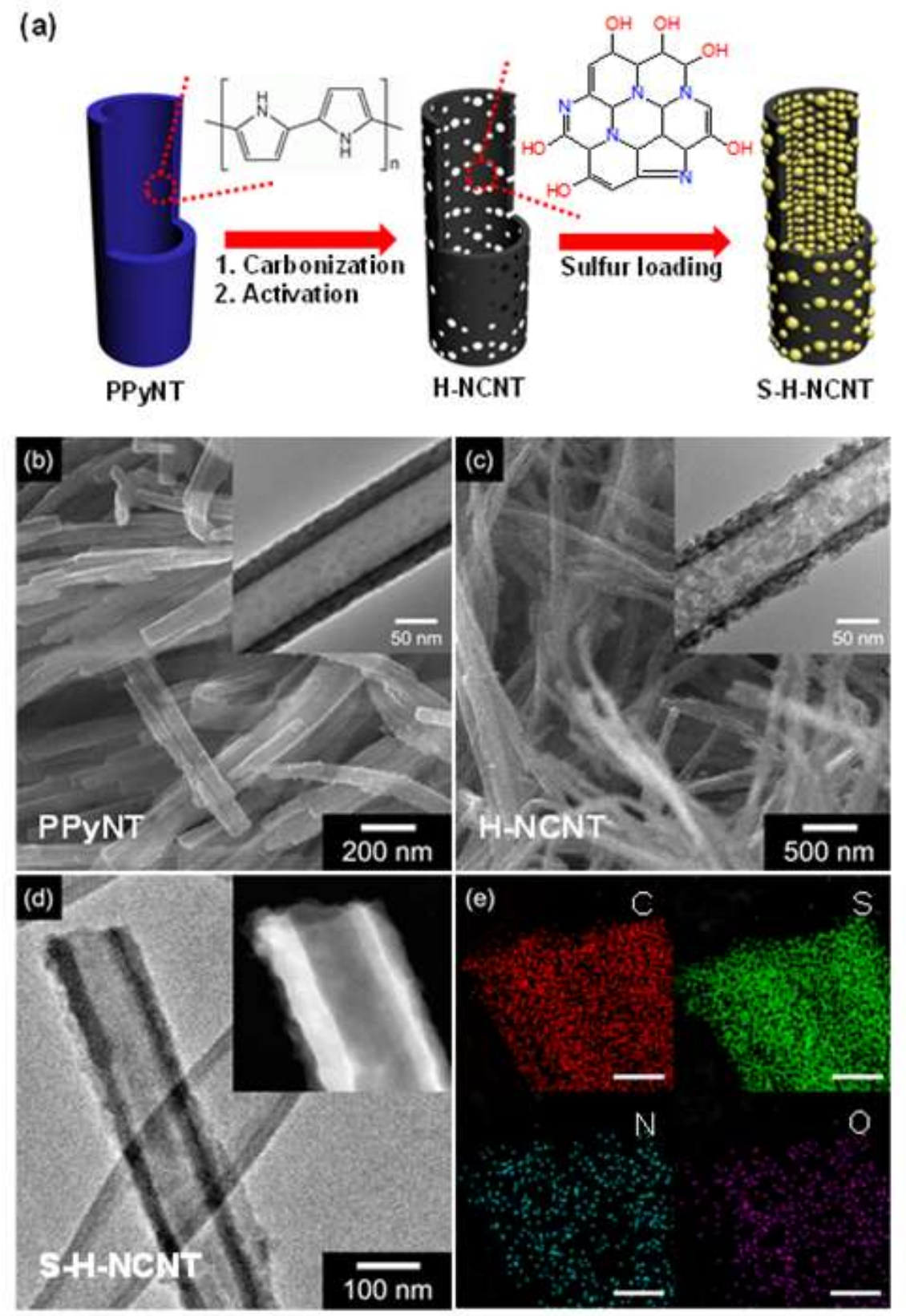

Fig. 1. (a) Illustrative of the sequential synthesis of the hydroxylated N-doped carbon nanotube-sulfur composites. Field-emission scanning electron microscopy (FE-SEM) and transmission electron microscopy (TEM) (inset) images of (b) the polypyrrole nanotubes and (c) the hydroxylated N-doped carbon nanotubes. (d) TEM (inset: scanning transmission electron microscopy (STEM)) images and (e) electron energy loss spectroscopy (EELS) dot mapping of the hydroxylated N-doped carbon nanotubesulfur composites. (scale bar: $20 \mathrm{~nm}$ ).

To verify the structural change in the carbon nanotubes with the activation process, BrunauerEmmett-Teller (BET) and Barret-Joyner-Halenda (BJH) measurements were conducted. Fig. 2a shows the $\mathrm{N}_{2}$ adsorption/desorption isotherms collected with the BET method for different carbon nanotubes (NCNT and H-NCNT). The isotherm of the carbon nanotubes suggests type IV hysteresis. The low 
pressure region $\left(0-0.2 \mathrm{P} / \mathrm{P}_{0}\right)$ indicates the presence of micropores and the high pressure region $(>0.8$ $\mathrm{P} / \mathrm{P}_{0}$ ) shows the existence of micropores. The surface area of the carbon nanotubes increases with activation: $873 \mathrm{~m}^{2} \mathrm{~g}^{-1}$ for H-NCNT compared to $212 \mathrm{~m}^{2} \mathrm{~g}^{-1}$ for NCNT. Moreover, the pore size distributions of the carbon nanotubes estimated by the BJH method, as demonstrated in Fig. 2b, verifies the formation of different pore sizes during the activation. The H-NCNT shows the generation of small peaks at $1.8,2.3$, and $3.1 \mathrm{~nm}$ owing to carbon etching through the chemical redox process. However, the

(a)

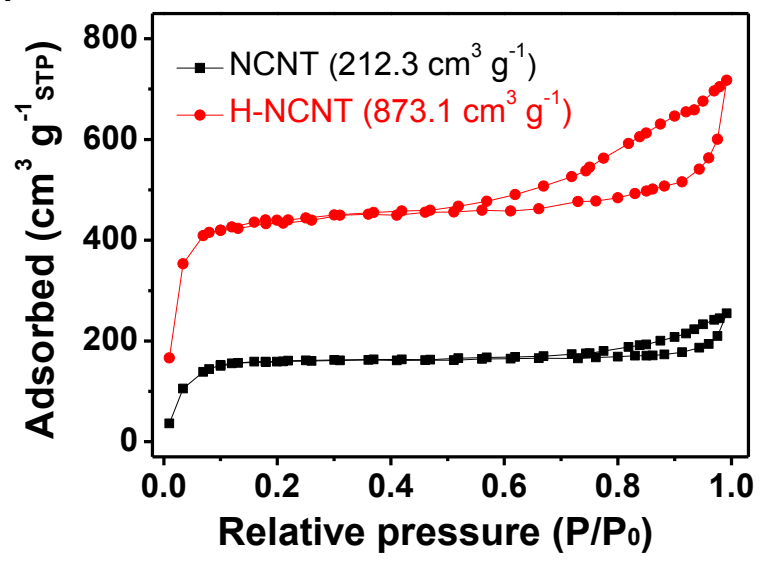

(b)

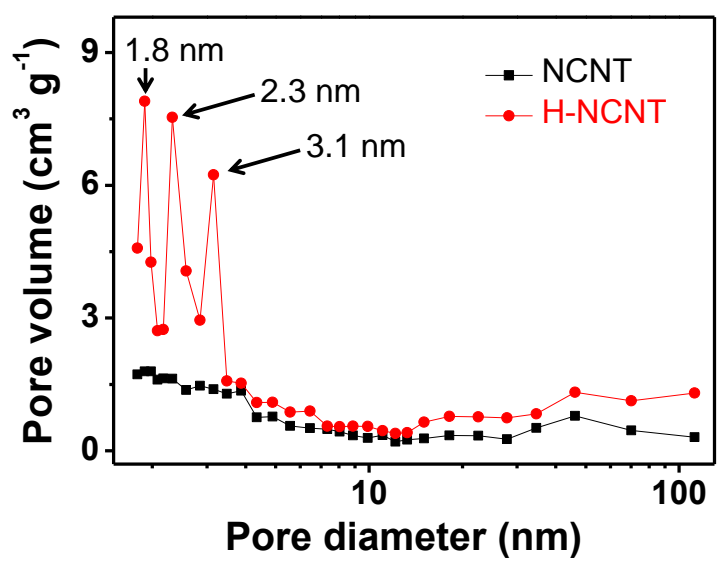

Fig. 2. (a) Nitrogen adsorption-desorption and (b) pore size distribution curves of the carbon nanotubes: NCNT (black); H-NCNT (red).

To verify the composition and crystallinity of the S-H-NCNT, thermogravimetric analysis (TGA) and X-ray diffraction (XRD) were performed. The XRD pattern of the pure sulfur and sulfur loaded carbon composites are suggested in Fig. 3a. A carbon/sulfur composite (S-NCNT) without the hydroxyl functional group shows diffraction peaks corresponding to orthorhombic sulfur (JCPDS 08-2047), indicating that sulfur particles exist on the carbon surface. In contrast, the S-H-NCNT with the hydroxyl groups displays no sulfur diffraction peaks since the sulfur is well confined within the carbon structure and the functional groups on the carbon surface prevent sulfur from growing into crystalline particles (Fig. 1 and Fig.S1). [35]. Fig. 3b presents the TGA curves of the pure sulfur and the sulfur/carbon 
composites (S-NCNT and S-H-NCNT). These samples suggest continuous weight loss from $180^{\circ} \mathrm{C}$ to $370^{\circ} \mathrm{C}$ in a nitrogen environment. The S-NCNT displays a ca. $55 \%$ weight loss, on the other hand, the S-H-NCNT shows a $c a .79 \%$ weight loss, which implies a high sulfur content of $79 \%$. Thus, the activated carbon framework contains more sulfur component with a strong interaction in the structure than that without the activation, owing to the functional groups on the surface of the carbon and small pores originating from the activation process. In addition, the S-H-NCNT displays higher sulfur vaporization temperature $\left(c a .235^{\circ} \mathrm{C}\right)$ than $\mathrm{S}-\mathrm{NCNT}\left(\mathrm{ca} .196^{\circ} \mathrm{C}\right)$ and pure sulfur $\left(c a .180^{\circ} \mathrm{C}\right)$, owing to the interaction between sulfur and the functional groups (hydroxide and nitrogen) and incorporation of sulfur into the small pores of carbon framework.[36] Therefore, S-H-NCNT exhibits higher binding between carbon and sulfur than others (S-NCNT and pure sulfur).

(a)

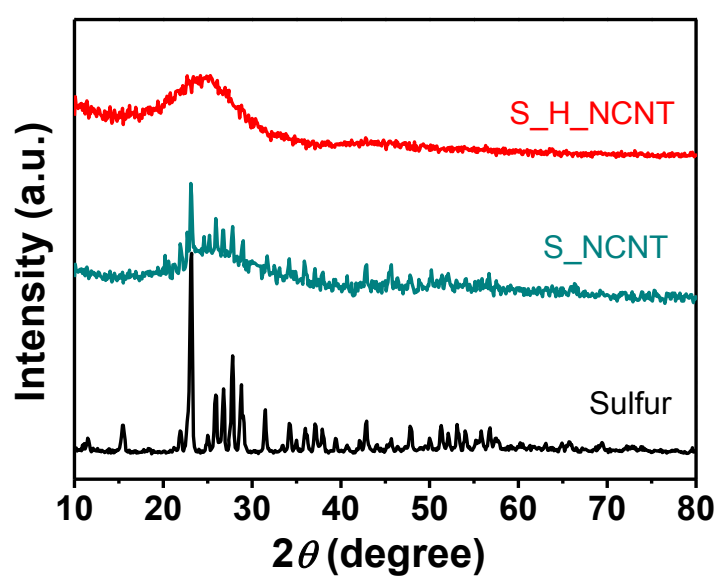

(b)

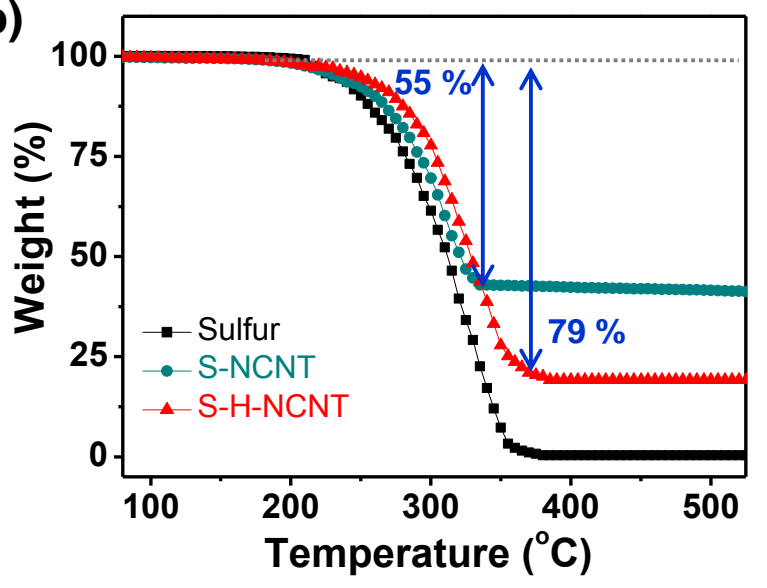

Fig. 3. (a) X-ray diffraction (XRD) patterns and (b) thermographic analysis (TGA) of pure sulfur (black), S-NCNT (green), and S-H-NCNT (red) composites.

The chemical composition of the composite is also analyzed in Fig. 4. Fig. 4a displays the overall range $(0-1100 \mathrm{eV})$ X-ray photoelectron spectra (XPS) of the composites (S-NCNT and S-H-NCNT). These overview spectra show $\mathrm{C}, \mathrm{N}, \mathrm{O}$, and $\mathrm{S}$ for both the samples, whereas the additional $\mathrm{K}$ element peak is only shown for the S-H-NCNT resulting from potassium residues at activation process, such as $\mathrm{K}_{2} \mathrm{CO}_{3}$ and $\mathrm{KOH}$. In addition, the $\mathrm{N}$ 1s region of the two composites also indicates the presence of nitrogen atoms in the carbon structure originating from polypyrrole chain (Fig. $\mathbf{4 b})$. Whereas there are 
differences at the $\mathrm{C} 1 \mathrm{~s}$ and the S 2p peaks between two composites. Fig. 4c shows the C 1s spectrum of S-NCNT contains six component peaks that are at $284.3 \mathrm{eV}$ for $\mathrm{C}=\mathrm{C}$ bond, $285.3 \mathrm{eV}$ for $\mathrm{C}-\mathrm{C}$ bond, $285.5 \mathrm{eV}$ for $\mathrm{C}-\mathrm{S}$ bond, $285.7 \mathrm{eV}$ for $\mathrm{C}-\mathrm{N}$ bond, $286.6 \mathrm{eV}$ for $\mathrm{C}-\mathrm{O}$ bonds (related to epoxy and hydroxyl group), and ca. $290 \mathrm{eV}$ for satellite graphite carbon. However, the intensity of the peak at $286.6 \mathrm{eV}$ for S-H-NCNT increases after chemical redox activation as shown in Fig. 4d. Furthermore, the S 2p region of the S-H-NCNT peaks present increase bonding with oxygen (168.1 eV and $169.3 \mathrm{eV})$, which are related to the hydroxyl group in the carbon structure (Fig. 4e and f). Therefore, these spectral investigations illustrate that the oxygen related groups, such as epoxy and hydroxyl, are well functionalized and chemically bonded to sulfur component. Additionally, H-NCNT also displays higher adsorption ability for polysulfide $\left(\mathrm{Li}_{2} \mathrm{~S}_{\mathrm{X}}, 4<\mathrm{X} \leq 8\right)$ than NCNT due to the high affinity between sulfur

(a)

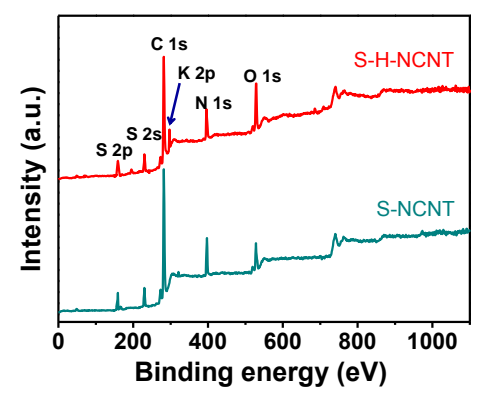

(b)

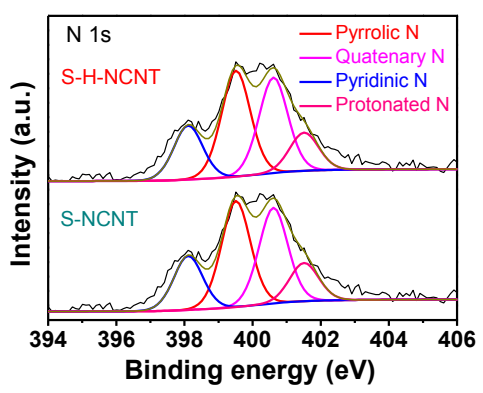

(c)

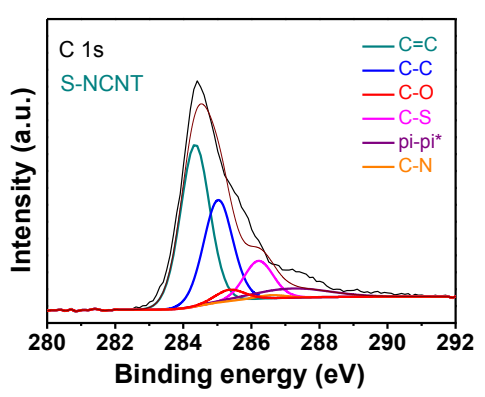

(d)

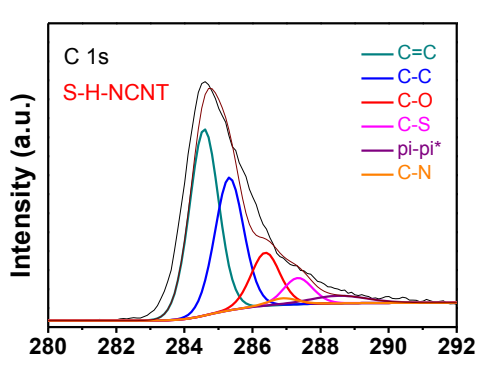

(e)

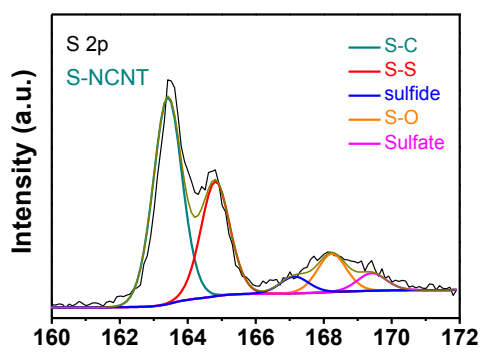

(f)

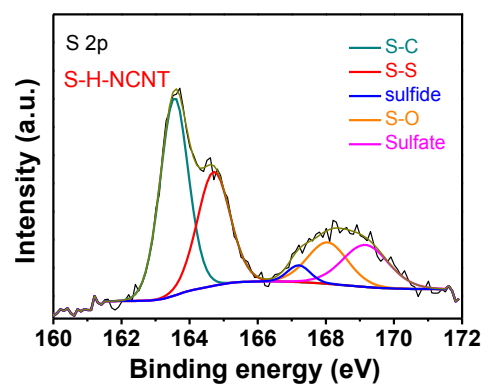

Fig. 4. (a) Fully scanned X-ray photoelectron spectra (XPS) of S-NCNT and S-H-NCNT. (b) N 1s XPS spectra of S-NCNT and S-H-NCNT. C 1s XPS spectra of (c) S-NCNT and (d) S-H-NCNT. S 2p XPS spectra of (e) S-NCNT and (f) S-H-NCNT. 
The electrochemical performances of the S-H-NCNT composite cathode were investigated by assembling CR2032 coin cells. Fig. 5a displays the cycle voltammetry (CV) curves of the cell within the voltage window of 1.8 to $2.8 \mathrm{~V}$ at scan rate of $0.2 \mathrm{mV} \mathrm{s}^{-1}$. Except for the $1^{\text {st }}$ cycle curve, the CV curves show complete overlapping of the characteristically cathodic and anodic peaks. Therefore, the S-HNCNT cathode maintains reversible capacity and prevents the polysulfide shuttling during cycling. The galvanostatic charge-discharge curves of the S-H-NCNT cathode containing $2.2 \mathrm{mg} \mathrm{cm}^{-2}$ of sulfur within the voltage window of 1.8 to $2.8 \mathrm{~V}$ at different current rates are shown in Fig. 5b. The discharge curves of the electrodes display the typical two-plateaus that are associated with the formation of longchain polysulfides $\left(\mathrm{Li}_{2} \mathrm{~S}_{\mathrm{x}}, 4<\mathrm{X}<8\right)$ at $2.3 \mathrm{~V}$ and short-chain polysulfides $\left(\mathrm{Li}_{2} \mathrm{~S}_{2}\right.$ and $\left.\mathrm{Li}_{2} \mathrm{~S}\right)$ at $2.1 \mathrm{~V}$ with a large flat region. In particular, the voltage profiles exhibit a uniform pattern of curves with increasing current density from $0.2 \mathrm{C}$ to $5 \mathrm{C}$ rates. The calculated capacities of the electrodes cycled at different current densities are shown in Fig. 5c. The initial specific discharge capacities of the composite is high enough $\left(1341 \mathrm{mAh} \mathrm{g}^{-1}\right)$ at $0.2 \mathrm{C}$ rate. Then, it maintains a reasonable capacity of as high as $849 \mathrm{mAh} \mathrm{g}^{-1}$ at $5 \mathrm{C}$ rate. The specific capacity also remains as high as $69 \%$ of the initial value (i.e., $0.06 \%$ capacity fade per cycle) after 500 cycles at $0.5 \mathrm{C}$ rate. Furthermore, the Coulombic efficiency of the S-H-NCNT remains above $99.5 \%$, illustrating restricted polysulfide dissolution into the electrolyte. The enhanced cycle stability of S-H-NCNT originates from its unique structure and the functional groups in the carbon framework. First, the hydroxyl groups and nitrogen doping on the surface increase the adsorption of the sulfur and polysulfide ions on the carbon by hydrogen bonding [35]. Second, the micropores generated from the activation step serve not only as traps for the sulfur and polysulfide ions but also as mini electrochemical reaction chambers [37].

In addition, the S-H-NCNT composite presents high capacity with good cycling stability at a high sulfur loading of $5.1 \mathrm{mg} \mathrm{cm}^{-2}$ (Fig. 5d and e). The high-sulfur-loading electrode shows lower initial capacity than that of the low-loading electrode $\left(2.2 \mathrm{mg} \mathrm{cm}^{-2}\right)$ owing to the decreasing interfacial area between the electrolyte and sulfur with an increasing thickness of the active material. Nevertheless, it 
still displays a high capacity (1081 $\mathrm{mAh} \mathrm{g}^{-1}$ at $0.2 \mathrm{C}$ rate), good rate capability (605 $\mathrm{mAh} \mathrm{g}^{-1}$ at $5 \mathrm{C}$ rate), and good cycle stability with $77 \%$ retention $\left(754 \mathrm{mAh} \mathrm{g}^{-1}\right)$ after 200 cycles at $0.5 \mathrm{C}$ rate. To elaborate, the $70 \mathrm{~nm}$-diameter longitudinal channels in the carbon nanotubes are filled with the electrolyte, which allows the sulfur in the S-H-NCNT to remain in contact with the electrolyte.

(a)

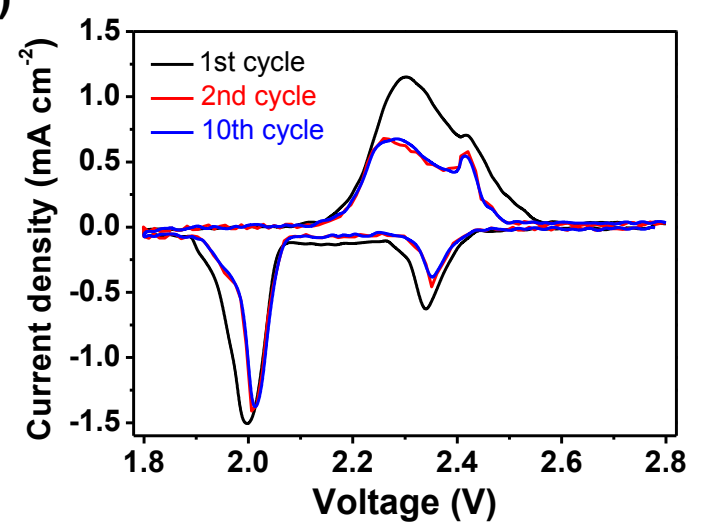

(b)

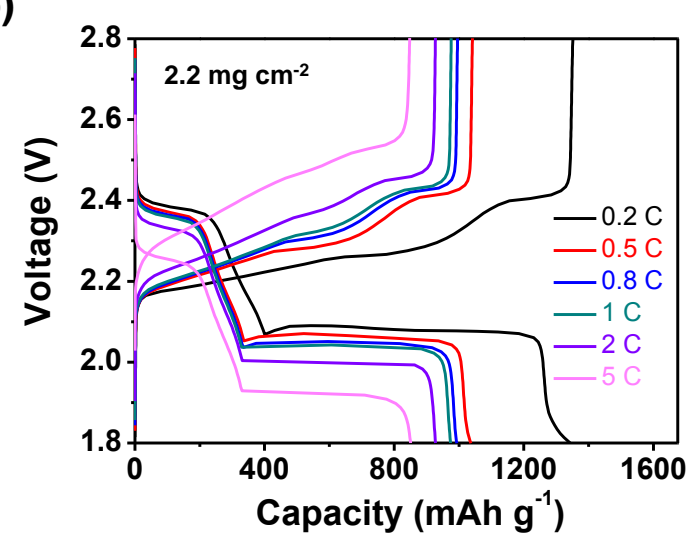

(c)

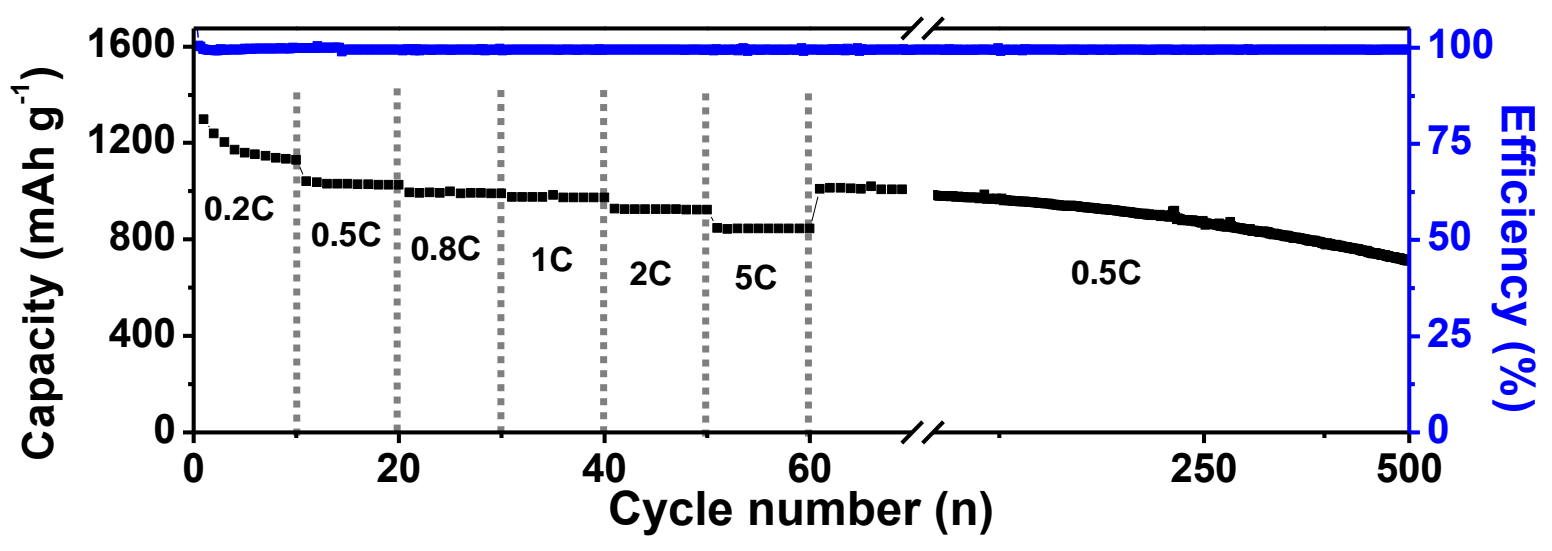

(d)

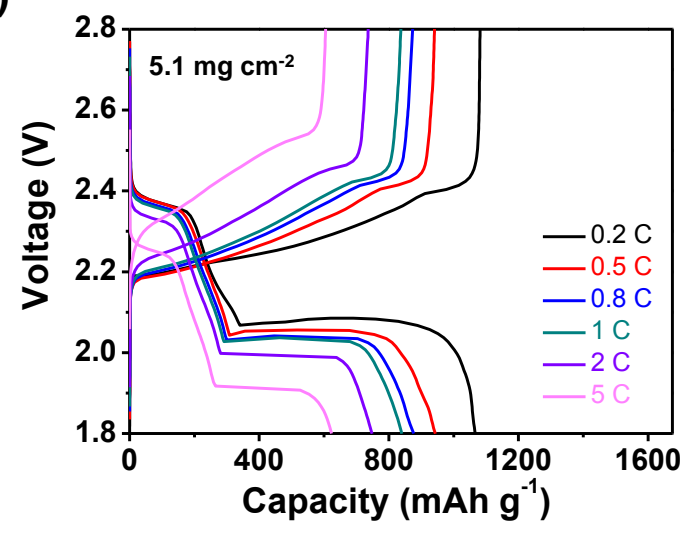

(e)

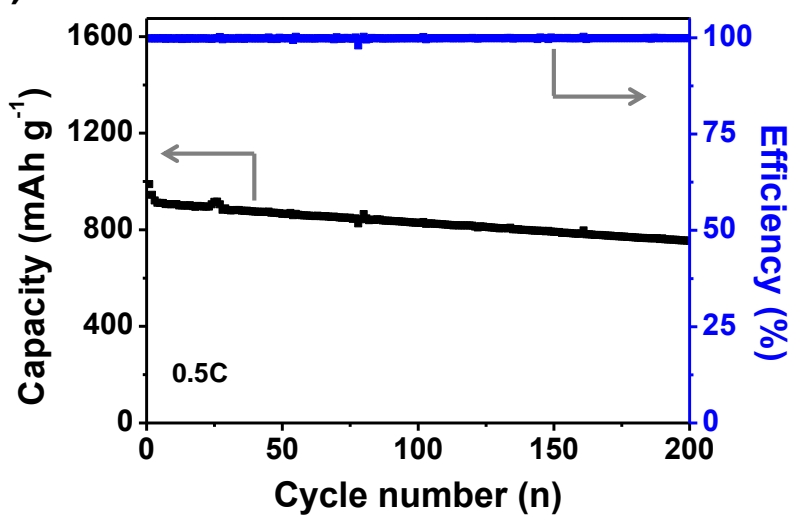

Fig. 5. (a) Cyclic voltammograms (at $0.2 \mathrm{mV} \mathrm{s}^{-1}$ ) of S-H-NCNT cathode. (b) Voltage profiles of the SH-NCNT cathode cycled between 1.8 and $2.8 \mathrm{~V}$ under increasing $\mathrm{C}$ rates. (c) Discharge capacity and Coulombic efficiency of S-H-NCNT over 500 cycles under increasing C rates. (d) Voltage profiles of the high-loading $\left(5.1 \mathrm{mg} \mathrm{cm}^{-2}\right) \mathrm{S}-\mathrm{H}-\mathrm{NCNT}$ between 1.8 and $2.8 \mathrm{~V}$ under increasing $\mathrm{C}$ rates. (e) 
Discharge capacity and Coulombic efficiency of high-loading sulfur composite electrode over 200 cycles at $0.5 \mathrm{C}$ rate.

\section{Conclusion}

In summary, hydroxylated N-doped carbon nanotube sulfur-composites (S-H-NCNT) have been synthesized by a facile method of radical polymerization and a subsequent activation process for application in lithium-sulfur (Li-S) batteries as a cathode material. The nitrogen atoms and hydroxyl groups in the H-CNT induce a nanoscale decoration of sulfur and allow the incorporation of a large amount of sulfur, as much as 79 wt.\% in the carbon structure. The S-H-NCNT based-electrodes display excellent cycle stability ( $712 \mathrm{mAh} \mathrm{g}^{-1}$ after 500 cycles) and rate capability (849 $\mathrm{mAh} \mathrm{g}^{-1}$ at $\left.5 \mathrm{C}\right)$ owing to their function as trap sites by the hydroxyl groups aided by nitrogen atoms and electrolyte penetration into the channel structure. Furthermore, this composite-based electrode exhibits high performance at a

high sulfur loading $\left(5.1 \mathrm{mg} \mathrm{cm}^{-2}\right)$ by retaining the interface between the electrolyte and the active material through the channel structure. This study represents an effective strategy to solve the critical problems of Li-S batteries.

\section{Acknowledgements}

This work was supported by the U.S. Department of Energy, Office of Basic Energy Sciences, Division of Materials Science and Engineering under award number DE-SC0005397. 


\section{References}

[1] W. J. Chung, J. J. Griebel, E. T. Kim, H. Yoon, A. G. Simmonds, H. J. Ji, P. T. Dirlam, R. S. Glass, J. J. Wie, N. A. Nguyen, B. W. Guralnick, J. Park, A. Somogyi, P. Theato, M. E. Mackay, Y-E. Sung, K. Char, J. Pyun, Nat. Chem. 5 (2013) 518-524.

[2] X. Liang, C. Hart, Q. Pang, A. Garsuch, T. Weiss, L.F. Nazar, Nat. Commun. 6 (2015) 5682-5689.

[3] W. Zhou, Y. Yu, H. Chen, F. J. DiSalvo, H. D. Abruna, J. Am. Chem. Soc. 135 (2013) 16736-16743.

[4] S. Moon, Y. H. Jung, W. K. Jung, D. S. Jung, J. W. Choi, D. K. Kim, Adv. Mater. 25 (2013) 65476553.

[5] Z. Li, X. Li, Y. Liao, X. Li, W. Li, J. Power Sources 334 (2016) 23-30.

[6] X-P. Gao, H-X. Yang, Energy Environ. Sci. 3 (2010) 174-189.

[7] X. Ji, S. Evers, R. Black, L. F. Nazar, Nat. Commun. 2 (2011) 325-331.

[8] K. Park, J. H. Cho, J-H. Jang, B-C. Yu, A. T. De La Hoz, K. M. Miller, C. J. Ellison, J. B. Goodenough, Energy Environ. Sci. 8 (2015) 2389-2395.

[9] Y. Chen, X. Li, K-S. Park, J. Hong, J. Song, L. Zhou, Y-M. Mai, H. Huang, J. B. Goodenough, J. Mater. Chem. A 2 (2014) 10126-10130.

[10] H. Sohn, D. H. Kim, R. Yi, D. Tang, S-E. Lee, Y. S. Jung, D. Wang, J. Power Sources 334 (2016) 128-136.

[11] J. Song, M. L. Gordin, T. Xu, S. Chen, Z. Yu, H. Sohn, J. Lu, Y. Ren, Y. Duan, D. Wang, Angew. Chem. Int. Ed. 54 (2015) 4325-4329.

[12] H. Wang, Y. Yang, Y. Liang, J. T. Robinson, Y. Li, A. Jackson, Y. Cui, H. Dai, Nano Lett. 11 (2011) 2644-2647. 
[13] C. Liang, N. J. Dudney, J. Y. Howe, Chem. Mater. 21 (2009) 4724-4730.

[14] R. Carter, D. Ejorh, K. Share, A. P. Cohn, A. Douglas, N. Muralidharan, T. M. Tavor, C. L. Pint, J. Power Sources 330 (2016) 70-77.

[15] Z. Wang, J. Zhang, Y. Yang, X. Yue, X. Hao, W. Sun, D. Rooney, K. Sun, J. Power Sources 329 (2016) 305-313.

[16] G. Zheng, Y. Yang, J. J. Cha, S. S. Hong, Y. Cui, Nano Lett. 11 (2011) 4462-4467.

[17] Y-J. Choi, K-W. Kim, H-J. Ahn, J-H. Ahn, J. Alloys Compd. 449 (2008) 313-316.

[18] L. Ji, M. Rao, H. Zheng, L. Zhang, Y. Li, W. Duan, J. Guo, E. J. Cairns, Y. Zhang, J. Am. Chem. Soc. 133 (2011) 18522-18525.

[19] Z. Ma, Z. Li, K. Hu, D. Liu, J. Huo, S. Wang, J. Power Sources 325 (2016) 71-78.

[20] X. Ji, T. K. Lee, L. F. Nazar, Nat. Mater. 8 (2009) 500-506.

[21] Z. Li, Y. Huang, L. Yuan, Z. Hao, Y. Huang, Carbon 92 (2015) 41-63.

[22] C. Liang, N. J. Dudney, J. Y. Howe, Chem. Mater. 21 (2009) 4724-4730.

[23] D. Bresser, S. Passerini, B. Scrosati, Chem. Commun. 49 (2013) 10545-10562.

[24] A. Manthiram, Y. Fu, S-H. Chung, C. Zu, Y-S. Su, Chem. Rev. 114 (2014) 11751-11787.

[25] Z. W. She, H. Wang, P-C. Hsu, Q. Zhang, W. Li, G. Zheng, H. Yao, Y. Cui, Energy Environ. Sci.7 (2014) 672-676.

[26] G. Zhou, L. Li, C. Ma, S. Wang, Y. Shi, N. Koratkar, W. Ren, F. Li, H-M. Cheng, Nano Energy 11 (2015) 356-365.

[27] Z. Li, Y. Jiang, L. Yuan, Z. Yi, C. Wu, Y. Liu, P. Strasser, Y. Huang, ACS Nano 8 (2014) 92959303. 
[28] W. Zhang, D. Qiao, J. Pan, Y. Cao, H. Yang, X. Ai, Electrochim. Acta 87 (2013) 497-502.

[29] C. Zu, Y. Fu, A. Manthiram, J. Mater. Chem. A 1 (2013) 10362-10367.

[30] W. Zhai, W. Tu, Y. Liu, H. Gao, J. Yu, Y. Zhao, G. Li, Electrochim. Acta 219 (2016) 143-151.

[31] J. Y. Koh, S. Kim, M-S. Park, J. J. Yang, T. H. Yang, Y. Jung, Electrochim. Acta 212 (2016) 212216.

[32] S. Niu, G. Zhou, W. 1v, H. Shi, C. Luo, Y. Hem B. Li, Q-H. Yang, F. Kang, Carbon 109 (2016) 1-6.

[33] F. Chen, J. Yang, T. Bai, B. Long, X. Zhou, Electrochim. Acta 192 (2016) 99-109.

[34] M. A. Lillo-Rodenas, D. Cazorla-Amoros, A. Lineares-Spilano, Carbon 41 (2003) 267-275.

[35] C. Zu, A. Manthiram, Adv. Energy Mater. 3 (2013) 1008-1012.

[36] J. Guo, Y. xu, C. Wang, Nano Lett. 11 (2011) 4288-4294.

[37] Z. Li, Y. Jiang, L. Yuan, Z. Yi, C. Wu, Y. Liu, P. Strasser, Y. Huang, ACS Nano 8 (2014) 92959303. 


\section{Figure Captions}

Fig. 1. (a) Illustrative of the sequential synthesis of the hydroxylated N-doped carbon nanotube-sulfur composites. Field-emission scanning electron microscopy (FE-SEM) and transmission electron microscopy (TEM) (inset) images of (b) the polypyrrole nanotubes and (c) the hydroxylated N-doped carbon nanotubes. (d) TEM (inset: scanning transmission electron microscopy (STEM)) images and (e) electron energy loss spectroscopy (EELS) dot mapping of the hydroxylated N-doped carbon nanotubesulfur composites. (scale bar: $20 \mathrm{~nm}$ ).

Fig. 2. (a) Nitrogen adsorption-desorption and (b) pore size distribution curves of the carbon nanotubes: NCNT (black); H-NCNT (red).

Fig. 3. (a) X-ray diffraction (XRD) patterns and (b) thermographic analysis (TGA) of pure sulfur (black), S-NCNT (green), and S-H-NCNT (red) composites.

Fig. 4. (a) Fully scanned X-ray photoelectron spectra (XPS) of S-NCNT and S-H-NCNT. (b) N 1s XPS spectra of S-NCNT and S-H-NCNT. C 1s XPS spectra of (c) S-NCNT and (d) S-H-NCNT. S 2p XPS spectra of (e) S-NCNT and (f) S-H-NCNT.

Fig. 5. (a) Cyclic voltammograms (at $0.2 \mathrm{mV} \mathrm{s}^{-1}$ ) of S-H-NCNT cathode. (b) Voltage profiles of the SH-NCNT cathode cycled between 1.8 and 2.8 V under increasing C-rates. (c) Discharge capacity and Coulombic efficiency of the S-H-NCNT over 500 cycles under increasing C-rates. (d) Voltage profiles

of the high-loading $\left(5.1 \mathrm{mg} \mathrm{cm}^{-2}\right) \mathrm{S}-\mathrm{H}-\mathrm{NCNT}$ between 1.8 and $2.8 \mathrm{~V}$ under increasing C-rates. (e) Discharge capacity and Coulombic efficiency of high-loading sulfur composite electrode over 200 cycles at $0.5 \mathrm{C}$ rate. 
(a)
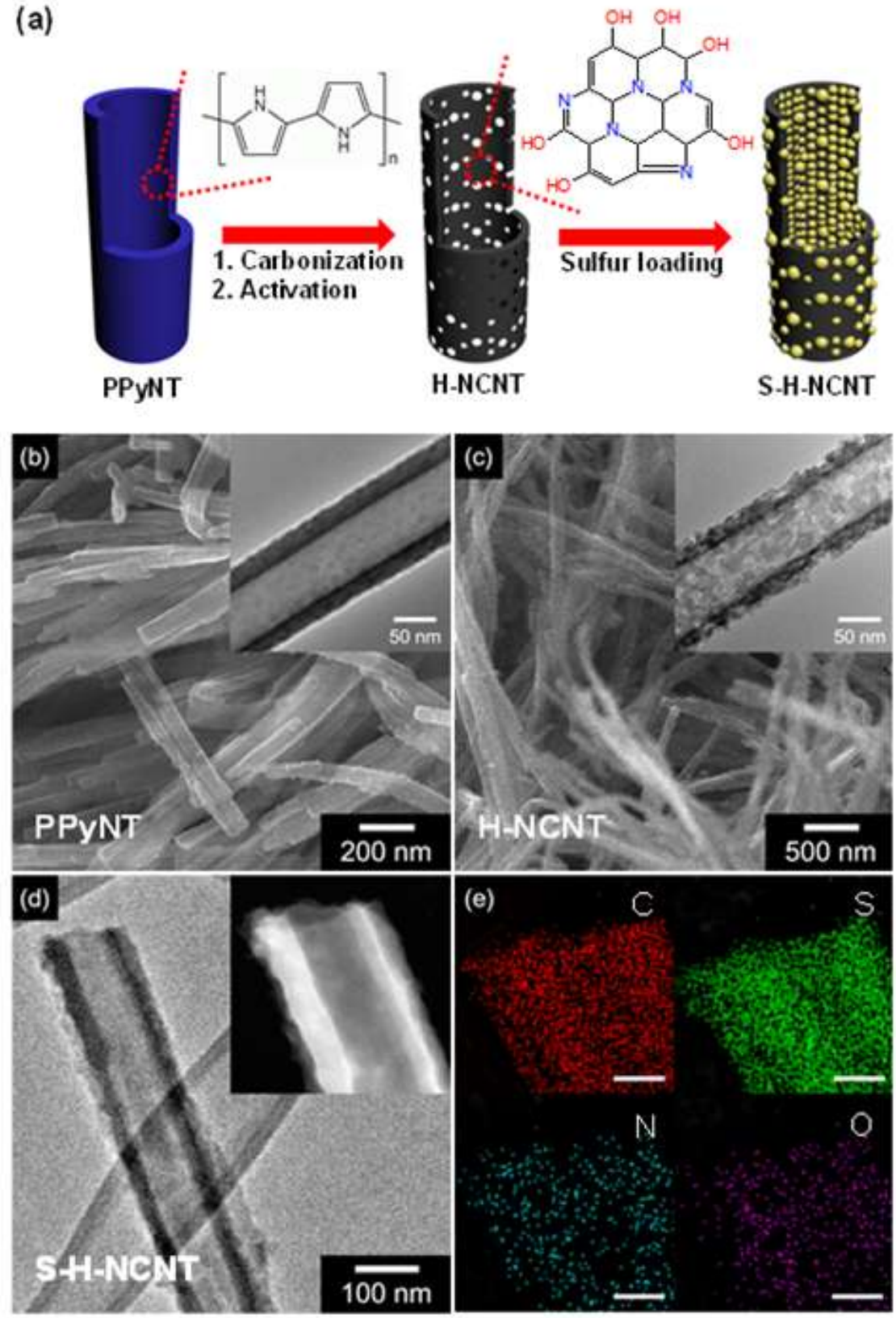

Fig. 1 
(a)

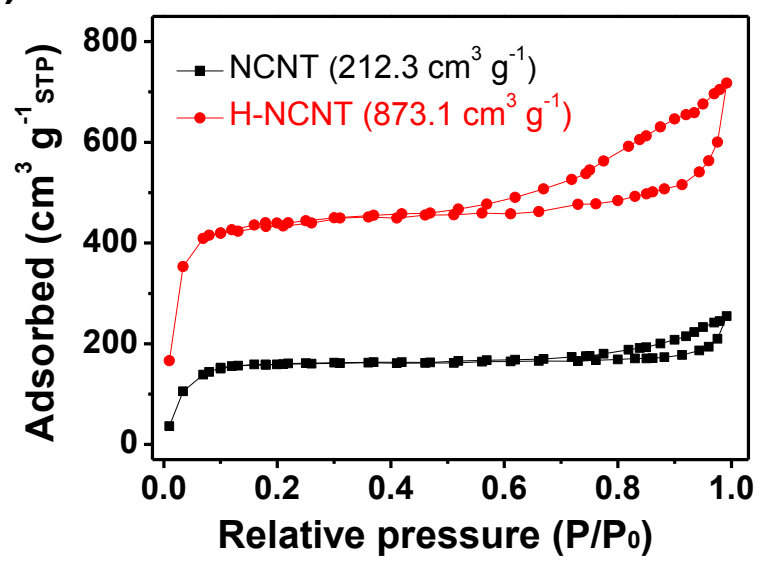

(b)

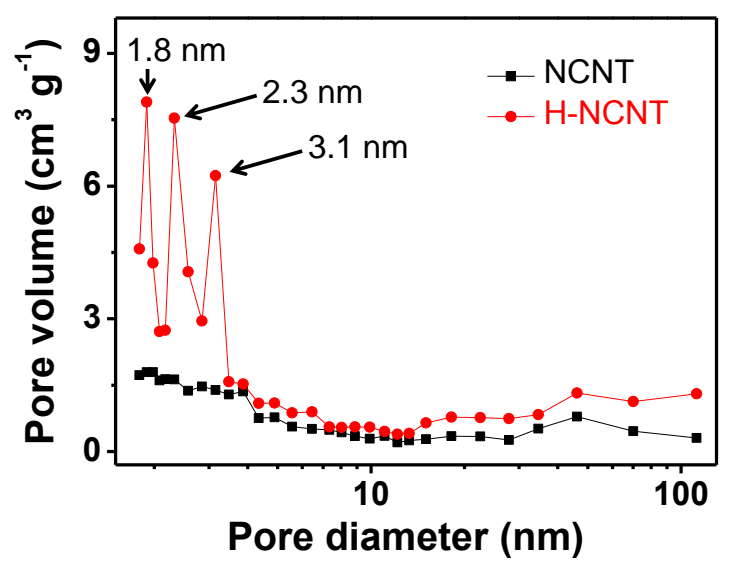

Fig. 2 
(a)

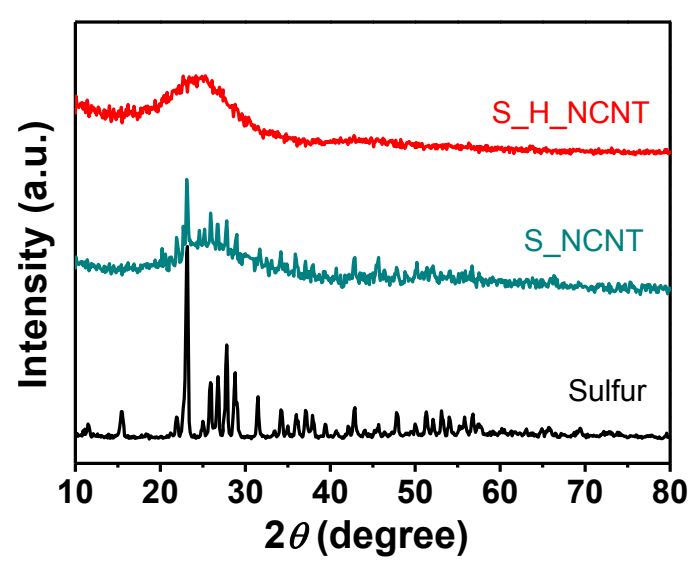

(b)

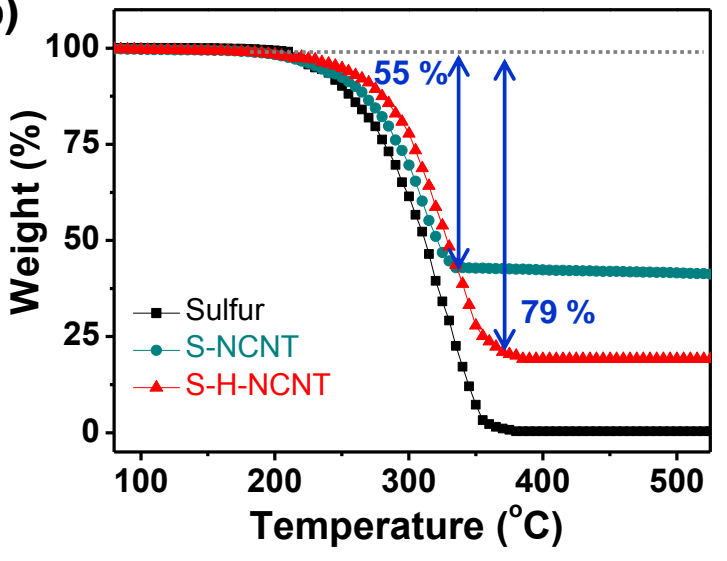

Fig. 3 
(a)

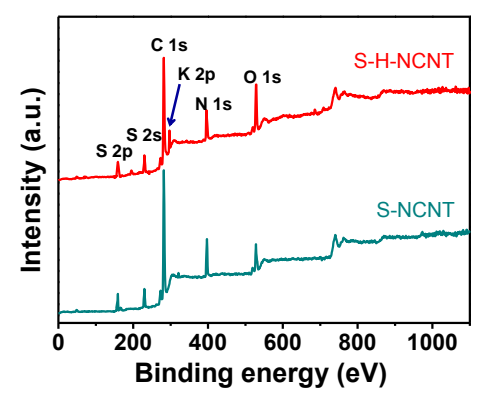

(b)

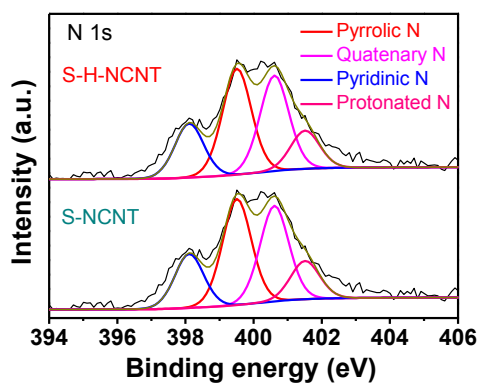

(c)

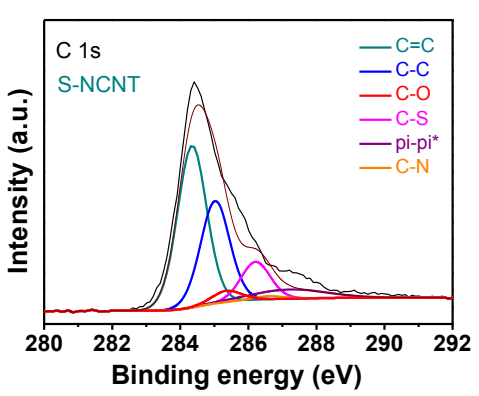

(d)

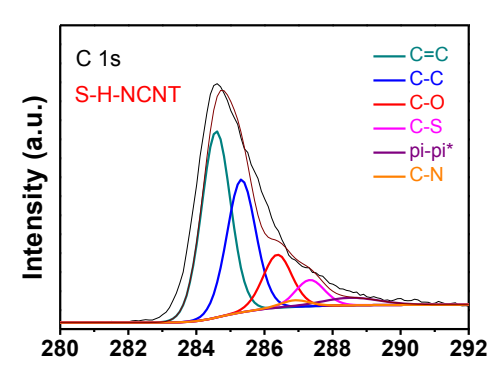

(e)

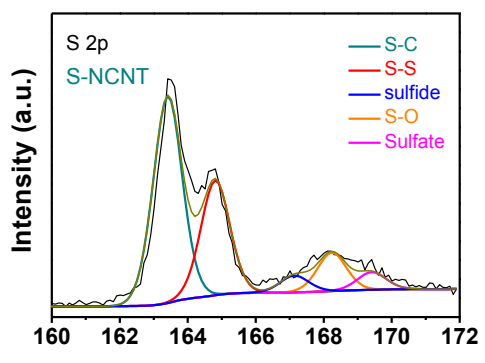

(f)

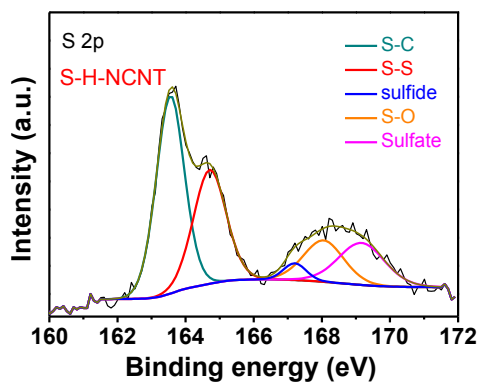

Fig. 4 
(a)

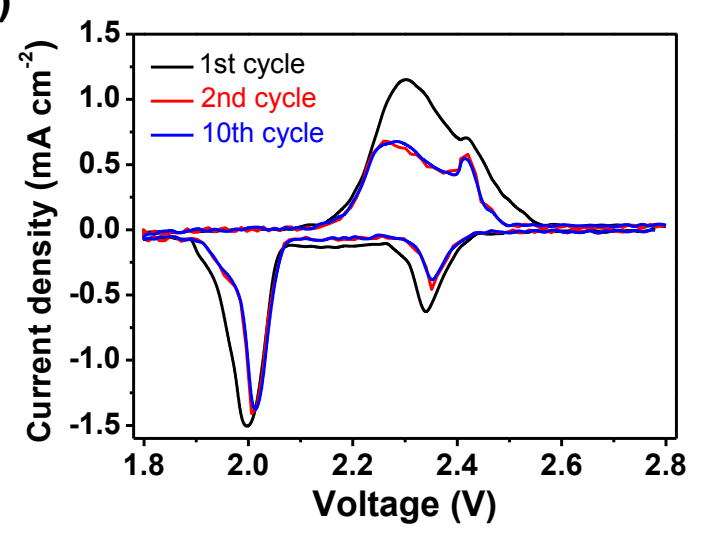

(b)

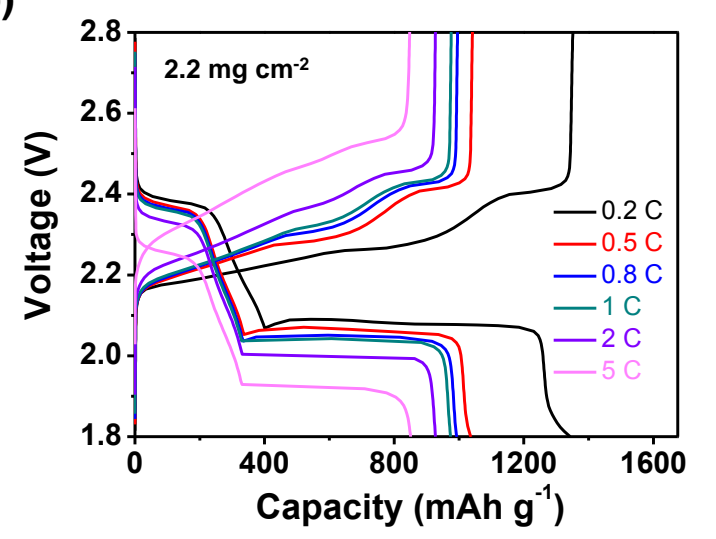

(c)

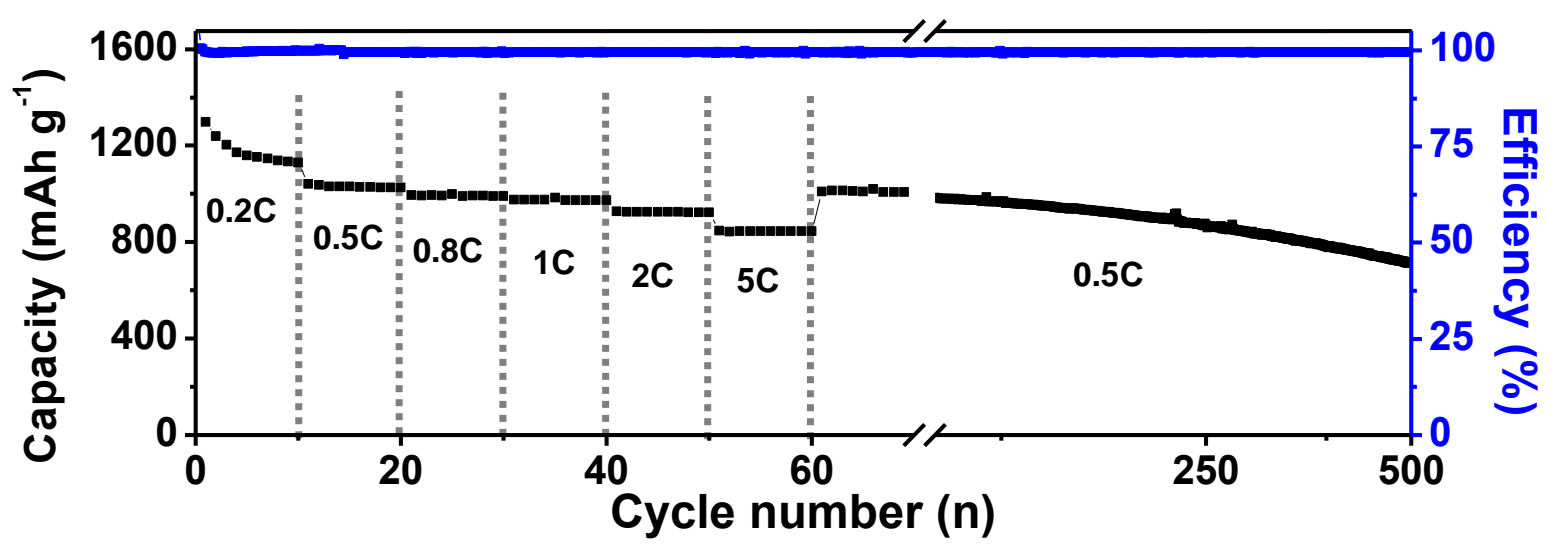

(d)

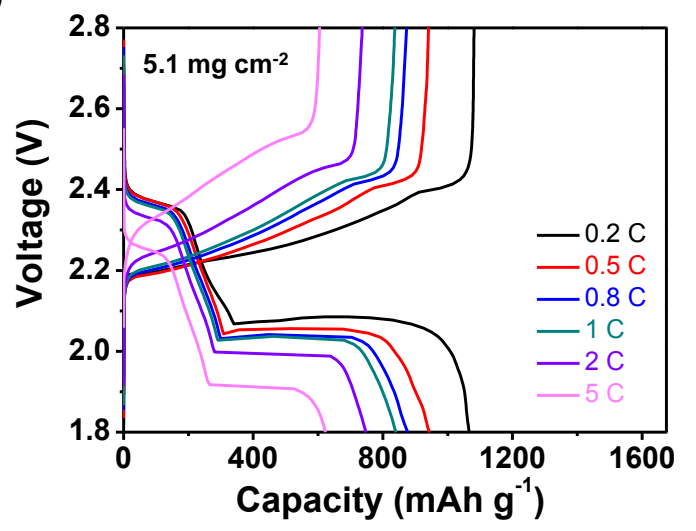

(e)

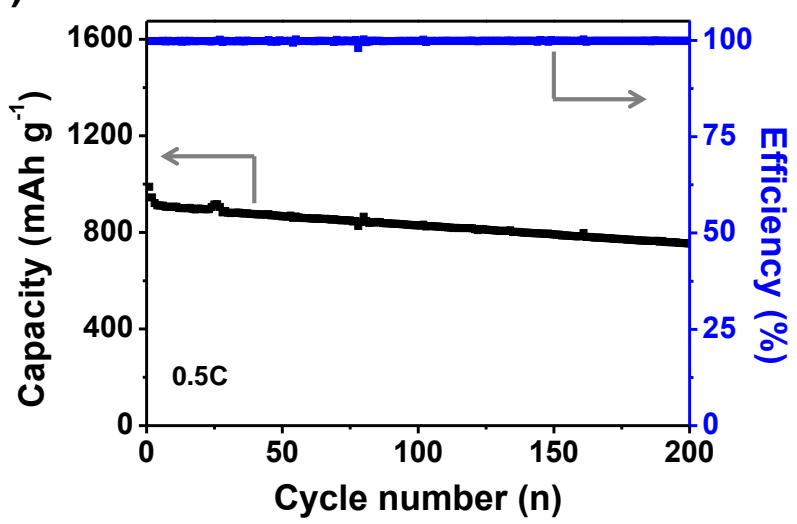

Fig. 5 